\title{
Thyroid Gland Malignant Peripheral Nerve Sheath Tumor
}

National Cancer Institute

\section{Source}

National Cancer Institute. Thyroid Gland Malignant Peripheral Nerve Sheath Tumor. NCI

Thesaurus. Code C156341.

A rare malignant peripheral nerve sheath tumor that arises from the thyroid gland. 